\title{
Treating Arterial Stiffness in Metabolic Syndrome and Type 2 Diabetes Mellitus
}

\author{
Niki Katsiki ${ }^{1}$, Eugenia Gkaliagkousi ${ }^{1}$, Asterios Karagiannis ${ }^{1}$ and Dimitri P. Mikhailidis ${ }^{2, *}$ \\ ${ }^{1} 2^{\text {nd }}$ Propedeutic Department of Internal Medicine, Aristotle University, Thessaloniki, Greece; ${ }^{2}$ Department of Clinical \\ Biochemistry (Vascular Disease Prevention Clinic) and Department of Surgery, Royal Free Campus, University College \\ London Medical School, University College London (UCL), London, UK
}

\begin{abstract}
Arterial stiffening characterizes ageing and several diseases related to increased cardiovascular (CV) risk such as the metabolic syndrome (MetS), type 2 diabetes mellitus (T2DM), hypertension, obesity and smoking. Several studies have shown that arterial stiffness is a strong, independent predictor of CV morbidity and mortality risk in such patient populations. Lifestyle measures and drugs frequently prescribed in MetS and T2DM patients such as hypolipidaemic, antihypertensive, hypoglycaemic and antiplatelet agents, may improve arterial stiffness, thus further reducing vascular risk. The current review considers the effects of these drugs and lifestyle changes on arterial stiffness in MetS and T2DM patients. The potential clinical implications of such effects on treatment decisions in clinical practice remain to be established. Multifactorial interventions may be even more beneficial in terms of CV risk reduction and thus their impact on arterial stiffness should also be evaluated.
\end{abstract}

Keywords: Antihypertensive, antiplatelet drugs, arterial stiffness, hypoglycaemic, hypolipidaemic drugs, metabolic syndrome, type 2 diabetes mellitus.

\section{INTRODUCTION}

Arterial stiffening characterizes ageing and several diseases related to increased cardiovascular (CV) risk such as the metabolic syndrome (MetS), type 2 diabetes mellitus (T2DM), hypertension, obesity and smoking [1-6]. Pulse wave velocity (PWV), a marker of arterial stiffness, can be non-invasively estimated by the evaluation of waveforms in the carotid and femoral or radial artery using certain devices (Sphygmocor and Complior are the most widely used) [7]. The carotid-femoral PWV (cfPWV) is currently considered the 'gold standard'; the recent 2013 guidelines of the European Society of Hypertension/European Society of Cardiology recommend the measurement of cfPWV in hypertensive patients to detect large artery stiffening (IIa-B level of evidence) [8].

Previous large long-term studies showed that increased arterial stiffness, as assessed by PWV, can independently predict CV morbidity and mortality, as well as all-cause mortality in different patient groups including those with MetS [9] and T2DM [10] as well as in the general population $[11,12]$. These associations were also supported by metaanalyses [13]; an increase in PWV by $1 \mathrm{~m} / \mathrm{sec}$ was related to $15 \%$ increments in CV morbidity and mortality as well as all-cause mortality. Furthermore, arterial stiffness evaluation was reported to lead to the re-classification of patients into different $\mathrm{CV}$ risk categories, thus contributing a significant

\footnotetext{
*Address correspondence to this author at the Department of Clinical Biochemistry (Vascular Disease Prevention Clinic), Royal Free Hospital Campus, University College London Medical School, University College London (UCL), Pond Street, London NW3 2QG, UK; Tel: +44 207830 2258; Fax: +44 207830 2235; E-mail: mikhailidis@aol.com
}

additive value in $\mathrm{CV}$ risk prediction beyond traditional risk factors, including the SCORE and Framingham risk scores $[8,14,15]$.

Based on the above data, there is increasing interest about arterial stiffness in the pathophysiology and management of patients with MetS and T2DM. The present review considers the effects of lifestyle measures as well as hypolipidaemic, antihypertensive, hypoglycaemic and antiplatelet drugs, that are frequently prescribed to these patients, on arterial stiffness. The potential clinical implications of such effects on treatment decisions in clinical practice remain to be established.

\section{LIFESTYLE MEASURES AND ARTERIAL STIFF- NESS}

Weight reduction by diet and exercise was reported to improve arterial stiffness in patients with MetS, even after a short period of time (i.e. 3 months) [16]. A greater reduction in arterial stiffness was observed when a low-calorie diet was combined with an intensive training course ( 2 sessions of $90 \mathrm{~min}, 3$ days per week) after only 7 weeks in morbidly obese individuals as compared with diet alone [17]. Of note, low-intensity exercise beneficially affected PWV only when combined with diet in obese postmenopausal women [18].

In an animal model, diet-induced obesity led to arterial stiffening within a month which preceded the development of hypertension by 5 months; weight loss resulted in normalization of both arterial stiffness and blood pressure [19]. Weight loss maintenance is also important for protecting the vasculature; among obese patients that successfully completed a 6-month weight reduction program, arterial stiffness was decreased only in those who maintained or even lowered 
their weight and not in those who regained weight within a period of 30 months [20].

The Amsterdam Growth and Health Longitudinal Study [21] showed that lower lifetime consumption of fiber, fruits, vegetables and whole-grains in young ages was associated with stiffer carotid arteries in adulthood. Similar results were obtained in the Cardiovascular Risk in Young Finns Study (duration $=27$ years) with regard to lifetime fruit and vegetable intake [22]. Milk and dairy products, except butter, seem to protect against increased arterial stiffness as shown in a cohort of the Caerphilly Prospective Study [23] and in a subset analysis of the Maine-Syracuse Longitudinal Study [24]. Salt substitutes with reduced-sodium and increasedpotassium content can reduce arterial stiffness over a 12month period [25]. Cranberry juice and ginseng have been also reported to improve arterial stiffness in some studies $[26,27]$.

Physical activity and especially vigorous habitual exercise was related to decreased arterial stiffness in the Amsterdam Growth and Health Longitudinal Study population [28]. In the same context, fit men with MetS (mean age $=52 \pm 6$ years) had similar PWV with unfit men without MetS [29]. Short-term aerobic physical activity (i.e. 3 weeks) improved arterial stiffness in T2DM patients [30]. Overall, exercise training has been shown to ameliorate arterial remodeling and stiffening in MetS, hypertensive, T2DM and obese patients [31]. However, it was recently reported that PWV reductions induced by aerobic exercise of 3 months duration in older patients (mean age $69.3 \pm 0.6$ years) with T2DM, hypertension and hyperlipidaemia were attenuated in 6 months [32]. Similarly, PWV did not change after a 6-month supervised exercise program (3 days per week) in T2DM hypertensive individuals, thus possibly suggesting a resistance in exercise-induced vascular benefits [33].

Smoking is associated with several risk factors for CV disease such as dyslipidaemia, hypertension, T2DM, chronic kidney disease (CKD), non-alcoholic fatty liver disease (NAFLD), peripheral arterial disease (PAD) and MetS $[2,34,35]$. Similarly, smokers as well as passive smokers have increased arterial stiffness [3]. Statin treatment can decrease the high CV risk of current smokers [36]. Furthermore, smoking cessation may improve arterial elasticity $[37,38]$.

\section{HYPOLIPIDAEMIC DRUGS AND ARTERIAL STIFFNESS}

Statin-induced beneficial effects on arterial stiffness have been reported in several patient populations $[39,40]$ including MetS and T2DM patients [9]. In this context, atorvastatin [41,42], fluvastatin [43] and pitavastatin [44] were previously shown to improve arterial elasticity in diabetic individuals. Data on fibrates are scarce; in one study fenofibrate did not affect arterial stiffness in T2DM patients [45]. A recent study reported decreased arterial stiffness following treatment with extended-release niacin in MetS patients [46]; to our knowledge there are no data in diabetics. Overall, there is a need for further randomized trials investigating the impact of statins on arterial stiffness as conflicting results also exist [47].
Omega-3 polyunsaturated fatty acids when supplemented after experimental ovariectomy prevented arterial stiffening and hypertension development [48]. Similarly, they can reduce arterial stiffness in humans as reported in a previous systematic review [49].

\section{ANTIHYPERTENSIVE DRUGS AND ARTERIAL STIFFNESS}

Several studies have shown that antihypertensive drugs can reduce arterial stiffness [6,50] both after acute and longterm (12 months) antihypertensive therapy $[51,52]$.

Calcium antagonists, angiotensin converting enzyme inhibitors (ACEi), angiotensin receptor blockers (ARBs), diuretics and vasodilating beta-blockers have been reported to improve PWV without significant differences between drug categories [53-60]. Similar results are supported by metaanalyses for ACEi [61-63]; such improvements in arterial hemodynamics are independent of blood pressure lowering. In contrast, when augmentation index (AIx) is used to assess arterial stiffness, the effects of beta-blockers are markedly different than that of other antihypertensive drugs; betablockers increase AIx, partly due to reductions in heart rate, whereas other agents decrease AIx [64]. Interestingly, conventional beta-blockers (such as atenolol), although equally reducing PWV, are less beneficial on central hemodynamics and AIx, whereas the newer vasodilating beta-blockers (such as nebivolol, carvedilol, and labetalol) seem to share the benefits of the other antihypertensive drugs [55,59]. Aliskiren (a direct renin inhibitor), spironolactone and eplerenone were also reported to decrease PWV [53].

This theme is extensively discussed in another review of this special issue [65]. There is an unmet need for further large, randomized controlled trials to compare the effects of different antihypertensive agents on arterial stiffness. Furthermore, novel antihypertensive agents such as aldosterone synthase and neprilysin inhibitors, as well as new devices/procedures, including renal denervation and baroreceptor stimulation, are currently being investigated with regard to arterial remodeling [66].

\section{HYPOGLYCAEMIC DRUGS AND ARTERIAL STIFFNESS}

Hemoglobin $A_{1 c}\left(\mathrm{HbA}_{1 c}\right)$ has been related to increased PWV in a dose-depended way in the general population [67] as well as in patients with pre-diabetes [68], T2DM [69] or MetS [70], although conflicting results exist for older nondiabetic adults [71] and Korean T2DM patients [72]. Metformin was associated with improvements in arterial stiffness in patients with NAFLD [73] or polycystic ovary syndrome (PCOS) [74]; only one study evaluated the impact of metformin therapy on arterial stiffness in T2DM individuals, reporting no significant changes [75]. Insulin [76] as well as pioglitazone [77-79] and glimepiride [80] (but not glibenclamide $[81,82])$ were shown to decrease arterial stiffness in T2DM patients.

With regard to the incretins, sitagliptin [81] and liraglutide [83] did not affect arterial stiffness in T2DM individuals. However, data are scarce and further studies are needed with other gliptins and glucagon-like peptide-1 (GLP-1) analogues/agonists. 


\section{ANTIPLATELET DRUGS AND ARTERIAL STIFF- NESS}

There are no data on the effect of antiplatelet drugs (such as aspirin, clopidogrel, prasugrel and ticagrelor) on arterial stiffness. Only one recent study [84], evaluated the effects of cilostazol (vs placebo) on arterial stiffness in T2DM patients with MetS; no significant differences were found after 8 weeks of treatment in terms of both PVW and other inflammatory biomarkers except for soluble vascular cellular adhesion molecule-1 (sVCAM-1) which was reduced.

Anticogulants including warfarin, heparins, direct factor $\mathrm{Xa}$ inhibitors (rivaroxaban, apixaban) and direct thrombin inhibitors (dabigatran) have also not been studied with regard to arterial stiffness.

\section{MULTIFACTORIAL TREATMENT}

Several studies have shown the beneficial effects of multifactorial interventions (including lifestyle changes, hypolipidaemic, antihypertensive, antiplatelet, hypoglycaemic and antiobesity drugs) on CV risk reduction in different patient populations such as those with CKD [85], MetS [86,87] and T2DM $[88,89]$.

With regard to arterial stiffness, only one recently published study compared intensive multifactorial treatment versus routine care in T2DM patients [90]; after a mean follow-up of 6.2 years, those receiving multifactorial interventions had significantly lower PWV than those on routine care.

\section{CONCLUSIONS}

There is increasing interest in the role of arterial stiffness in the pathophysiology and management of patients with MetS and T2DM. Several studies have shown that arterial stiffness is a strong, independent predictor of CV risk in such patient populations. Lifestyle measures, hypolipidaemic, antihypertensive, hypoglycaemic and antiplatelet drugs, frequently prescribed in MetS and T2DM patients, may improve arterial stiffness, thus further reducing vascular risk. However, future research is needed to establish the role of arterial stiffness in clinical practice as well as in selecting the appropriate drugs when treating high-risk patients such as those with MetS and T2DM. Multifactorial interventions may be even more beneficial in terms of $\mathrm{CV}$ risk reduction and thus their effects on arterial stiffness should also be evaluated.

\section{CONFLICT OF INTEREST}

This review was written independently; no company or institution supported the authors financially or by providing a professional writer. Some of the authors have given talks, attended conferences and participated in trials and advisory boards sponsored by various pharmaceutical companies.

\section{ACKNOWLEDGEMENT}

Declared none.

\section{REFERENCES}

[1] Katsiki N, Athyros VG, Karagiannis A, Mikhailidis DP. Characteristics other than the diagnostic criteria associated with metabolic syndrome: an overview. Curr Vasc Pharmacol 2013 Apr 25. [Epub ahead of print]

Athyros VG, Katsiki N, Doumas M, Karagiannis A, Mikhailidis DP. Effect of tobacco smoking and smoking cessation on plasma lipoproteins and associated major cardiovascular risk factors: a narrative review. Curr Med Res Opin 2013; 29: 1263-74.

[3] Doonan RJ, Hausvater A, Scallan C, Mikhailidis DP, Pilote L, Daskalopoulou SS. The effect of smoking on arterial stiffness. Hypertens Res 2010; 33: 398-410.

[4] Seifalian AM, Filippatos TD, Joshi J, Mikhailidis DP. Obesity and arterial compliance alterations. Curr Vasc Pharmacol 2010; 8: 15568.

[5] Christen AI, Armentano RL, Miranda A, et al. Arterial wall structure and dynamics in type 2 diabetes mellitus methodological aspects and pathophysiological findings. Curr Diabetes Rev 2010; 6: 367-77.

[6] Koumaras C, Tzimou M, Stavrinou E, et al. Role of antihypertensive drugs in arterial 'de-stiffening' and central pulsatile hemodynamics. Am J Cardiovasc Drugs 2012; 12: 143-56.

[7] Huck CJ, Bronas UG, Williamson EB, Draheim CC, Duprez DA, Dengel DR. Noninvasive measurements of arterial stiffness: repeatability and interrelationships with endothelial function and arterial morphology measures. Vasc Health Risk Manage 2007; 3: 343-9.

[8] Mancia G, Fagard R, Narkiewicz K, et al. 2013 ESH/ESC guidelines for the management of arterial hypertension. J Hypertens 2013; 31:1281-357.

[9] Cernes R, Zimlichman R, Shargorodsky M. Arterial elasticity in cardiovascular disease: focus on hypertension, metabolic syndrome and diabetes. Adv Cardiol 2008; 45: 65-81.

[10] Mansour AS, Yannoutsos A, Majahalme N, et al. Aortic stiffness and cardiovascular risk in type 2 diabetes. J Hypertens 2013; 31:1584-92.

[11] Mitchell GF, Hwang SJ, Vasan RS, et al. Arterial stiffness and cardiovascular events. The Framingham Heart Study. Circulation 2010; 121: 505-11.

[12] Wang KL, Cheng HM, Sung SH, et al. Wave reflection and arterial stiffness in the prediction of 15-year all-cause and cardiovascular mortalities: a community-based study. Hypertension 2010; 55: 799805.

[13] Vlachopoulos C, Aznaouridis K, Stefanadis C. Prediction of cardiovascular events and all-cause mortality with arterial stiffness: a systematic review and meta-analysis. J Am Coll Cardiol 2010; 55: 1318-27.

[14] Seherstedt T, Jeppesen J, Hansen TW, et al. Risk prediction is improved by adding markers of subclinical organ damage to SCORE. Eur Heart J 2010; 31: 883-91.

[15] Seherstedt T, Jeppesen J, Hansen TW, et al. Thresholds for pulse wave velocity, urine albumin creatinine ratio and left ventricular mass index using SCORE, Framingham, and ESH/ESC risk charts. J Hypertens 2012; 30:1928-36.

[16] Iguchi A, Yamakage H, Tochiya M, et al. Effects of Weight Reduction Therapy on Obstructive Sleep Apnea Syndrome and Arterial Stiffness in Patients with Obesity and Metabolic Syndrome. J Atheroscler Thromb $2013 \mathrm{Jul} 25$ [Epub ahead of print]

[17] Nordstrand N, Gjevestad E, Hertel JK, et al. Arterial stiffness, lifestyle intervention and a low-calorie diet in morbidly obese patients-a nonrandomized clinical trial. Obesity (Silver Spring) 2013; 21: 690-7.

[18] Figueroa A, Vicil F, Sanchez-Gonzalez MA, et al. Effects of diet and/or low-intensity resistance exercise training on arterial stiffness, adiposity, and lean mass in obese postmenopausal women. Am J Hypertens 2013; 26: 416-23.

[19] Weisbrod RM, Shiang T, Al Sayah L, et al. F. Arterial Stiffening Precedes Systolic Hypertension in Diet-Induced Obesity. Hypertension 2013 Sep 23. [Epub ahead of print]

[20] Wolfson N, Garish D, Goldberg Y, Boaz M, Matas Z, Shargorodsky M. Effect of weight loss maintenance on arterial compliance and metabolic and inflammatory parameters: a three-year follow-up study. Ann Nutr Metab 2010; 57: 204-10.

[21] van de Laar RJ, Stehouwer CD, van Bussel BC, et al. Lower lifetime dietary fiber intake is associated with carotid artery stiffness: the Amsterdam Growth and Health Longitudinal Study. Am J Clin Nutr 2012; 96: 14-23.

[22] Aatola H, Koivistoinen T, Hutri-Kähönen N, et al. Lifetime fruit and vegetable consumption and arterial pulse wave velocity in 
adulthood: the Cardiovascular Risk in Young Finns Study. Circulation 2010; 122: 2521-8.

[23] Livingstone KM, Lovegrove JA, Cockcroft JR, Elwood PC, Pickering JE, Givens DI. Does dairy food intake predict arterial stiffness and blood pressure in men?: Evidence from the Caerphilly Prospective Study. Hypertension 2013; 61: 42-7.

[24] Crichton GE, Elias MF, Dore GA, Abhayaratna WP, Robbins MA. Relations between dairy food intake and arterial stiffness: pulse wave velocity and pulse pressure. Hypertension 2012; 59: 1044-51.

[25] Hu J, Jiang X, Li N, et al. Effects of salt substitute on pulse wave analysis among individuals at high cardiovascular risk in rural China: a randomized controlled trial. Hypertens Res 2009; 32: 2828.

[26] Ruel G, Lapointe A, Pomerleau S, et al. Evidence that cranberry juice may improve augmentation index in overweight men. Nutr Res 2013; 33: 41-9.

[27] Mucalo I, Jovanovski E, Rahelić D, Božikov V, Romić Z, Vuksan V. Effect of American ginseng (Panax quinquefolius L.) on arterial stiffness in subjects with type-2 diabetes and concomitant hypertension. J Ethnopharmacol 2013 Aug 22 [Epub ahead of print]

[28] van de Laar RJ, Ferreira I, van Mechelen W, Prins MH, Twisk JW, Stehouwer CD. Lifetime vigorous but not light-to-moderate habitual physical activity impacts favorably on carotid stiffness in young adults: the Amsterdam growth and health longitudinal study. Hypertension 2010; 55: 33-9.

[29] Jae SY, Heffernan KS, Fernhall B, et al. Association between cardiorespiratory fitness and arterial stiffness in men with the metabolic syndrome. Diabetes Res Clin Pract 2010; 90: 326-32.

[30] Yokoyama H, Emoto M, Fujiwara S, et al. Short-term aerobic exercise improves arterial stiffness in type 2 diabetes. Diabetes Res Clin Pract 2004; 65: 85-93.

[31] Roque FR, Hernanz R, Salaices M, Briones AM. Exercise training and cardiometabolic diseases: focus on the vascular system. Curr Hypertens Rep 2013; 15: 204-14.

[32] Madden KM, Lockhart C, Cuff D, Potter TF, Meneilly GS. Aerobic training-induced improvements in arterial stiffness are not sustained in older adults with multiple cardiovascular risk factors. J Hum Hypertens 2013; 27: 335-9.

[33] Dobrosielski DA, Gibbs BB, Ouyang P, et al. Effect of exercise on blood pressure in type 2 diabetes: a randomized controlled trial. J Gen Intern Med 2012; 27: 1453-9.

[34] Katsiki N, Athyros VG, Karagiannis A, Mikhailidis DP. Smoking and non-alcoholic steatohepatitis (NASH): the GREek Atorvastatin and Coronary heart disease Evaluation (GREACE) trial. J Hepatol 2012; 57: 476.

[35] Katsiki N, Papadopoulou SK, Fachantidou AI, Mikhailidis DP. Smoking and vascular risk: are all forms of smoking harmful to all types of vascular disease? Public Health 2013; 127: 435-41.

[36] Athyros VG, Tziomalos K, Katsiki N, et al, For The Greace Study Collaborative Group. The Impact of Smoking on Cardiovascular Outcomes and Comorbidities in Statin-treated Patients with Coronary Artery Disease: A Post hoc Analysis of the GREACE Study. Curr Vasc Pharmacol 2013; 11: 779-84.

[37] Takami T, Saito Y. Effects of smoking cessation on central blood pressure and arterial stiffness. Vasc Health Risk Manag 2011; 7: 633-8.

[38] Yu-Jie W, Hui-Liang L, Bing L, Lu Z, Zhi-Geng J. Impact of smoking and smoking cessation on arterial stiffness in healthy participants. Angiology 2013; 64: 273-80.

[39] Mäki-Petäjä KM, Wilkinson IB. Anti-inflammatory drugs and statins for arterial stiffness reduction. Curr Pharm Des 2009; 15: 290-303.

[40] Tziomalos K, Athyros VG, Karagiannis A, Mikhailidis DP. Endothelial function, arterial stiffness and lipid lowering drugs. Expert Opin Ther Targets 2007; 11: 1143-60.

[41] Mukherjee S, Mukhopadhyay P, Pandit K, Mukherjee S, Chowdhury S. Atorvastatin improves arterial stiffness in normotensive normolipidaemic persons with type 2 diabetes. J Indian Med Assoc 2008; 106: 716-9.

[42] Shinohara K, Shoji T, Kimoto E, et al. Effect of atorvastatin on regional arterial stiffness in patients with type 2 diabetes mellitus. $\mathrm{J}$ Atheroscler Thromb 2005; 12: 205-10.

[43] Ichihara A, Hayashi M, Ryuzaki M, Handa M, Furukawa T, Saruta T. Fluvastatin prevents development of arterial stiffness in haemodialysis patients with type 2 diabetes mellitus. Nephrol Dial Transplant 2002; 17: 1513-7.
[44] Miyashita Y, Endo K, Saiki A, et al. Effects of pitavastatin, a 3hydroxy-3-methylglutaryl coenzyme a reductase inhibitor, on cardio-ankle vascular index in type 2 diabetic patients. J Atheroscler Thromb 2009; 16: 539-45.

[45] Hiukka A, Westerbacka J, Leinonen ES, et al. Long-term effects of fenofibrate on carotid intima-media thickness and augmentation index in subjects with type 2 diabetes mellitus. J Am Coll Cardiol 20086; 52: 2190-7.

[46] Shearer GC, Pottala JV, Hansen SN, Brandenburg V, Harris WS. Effects of prescription niacin and omega-3 fatty acids on lipids and vascular function in metabolic syndrome: a randomized controlled trial. J Lipid Res 2012; 53: 2429-35.

[47] Rizos EC, Agouridis AP, Elisaf MS. The effect of statin therapy on arterial stiffness by measuring pulse wave velocity: a systematic review. Curr Vasc Pharmacol 2010; 8: 638-44.

[48] Losurdo P, Grillo A, Panizon E, et al. Supplementation of Omega-3 Polyunsaturated Fatty Acids Prevents Increase in Arterial Stiffness After Experimental Menopause. J Cardiovasc Pharmacol Ther 2013 Sep 13. [Epub ahead of print]

[49] Pase MP, Grima NA, Sarris J. The effects of dietary and nutrient interventions on arterial stiffness: a systematic review. Am J Clin Nutr 2011; 93: 446-54.

[50] Koumaras C, Tziomalos K, Stavrinou E, et al. Effects of reninangiotensin-aldosterone system inhibitors and beta-blockers on markers of arterial stiffness. J Am Soc Hypertens 2013 Oct 16. doi:pii: $\quad$ S1933-1711(13)00167-8. 10.1016/j.jash.2013.09.001. [Epub ahead of print]

[51] Ichihara A, Hayashi M, Koura Y, Tada Y, Hirota N, Saruta T. Long-term effects of intensive blood-pressure lowering on arterial wall stiffness in hypertensive patients. Am J Hypertens 2003; 16: 959-65.

[52] Mitchell GF, Lacourcière Y, Arnold JM, Dunlap ME, Conlin PR, Izzo JL Jr. Changes in aortic stiffness and augmentation index after acute converting enzyme or vasopeptidase inhibition. Hypertension 2005; 46: 1111-7.

[53] Dudenbostel T, Glasser SP. Effects of antihypertensive drugs on arterial stiffness. Cardiol Rev 2012; 20: 259-63.

[54] Adji A, O'Rourke MF, Namasivayam M. Arterial stiffness, its assessment, prognostic value, and implications for treatment. Am J Hypertens 2011;24: 5-17.

[55] Pedersen ME, Cockcroft JR. What is the role, if any, for betablockers as initial therapy for uncomplicated hypertension? Curr Opin Cardiol 2009; 24: 325-32.

[56] Pende A, Dallegri F. Renin-angiotensin antagonists: therapeutic effects beyond blood pressure control? Curr Pharm Des 2012; 18: 1011-20.

[57] Agarwal R. Antihypertensive agents and arterial stiffness: relevance to reducing cardiovascular risk in the chronic kidney disease patient. Curr Opin Nephrol Hypertens 2007; 16: 409-15.

[58] Andreadis EA, Sfakianakis ME, Tsourous GI, et al. Differential impact of angiotensin receptor blockers and calcium channel blockers on arterial stiffness. Int Angiol 2010; 29: 266-72.

[59] Agabiti-Rosei E, Porteri E, Rizzoni D. Arterial stiffness, hypertension, and rational use of nebivolol. Vasc Health Risk Manage 2009; 5: 353-60.

[60] Raij L, Gonzalez-Ochoa AM. Vascular compliance in blood pressure. Curr Opin Nephrol Hypertens 2011; 20: 457-64.

[61] Ong KT, Delerme S, Pannier B, et al; investigators. Aortic stiffness is reduced beyond blood pressure lowering by short-term and longterm antihypertensive treatment: a meta-analysis of individual data in 294 patients. J Hypertens 2011; 29: 1034-42.

[62] Shahin Y, Khan JA, Chetter I. Angiotensin converting enzyme inhibitors effect on arterial stiffness and wave reflections: a metaanalysis and meta-regression of randomised controlled trials. Atherosclerosis 2012; 221: 18-33.

[63] Mallareddy M, Parikh CR, Peixoto AJ. Effect of angiotensinconverting enzyme inhibitors on arterial stiffness in hypertension: systematic review and meta-analysis. J Clin Hypertens (Greenwich). 2006; 8: 398-403.

[64] Mackenzie IS, McEniery CM, Dhakam Z, et al. Comparison of the effects of antihypertensive agents on central blood pressure and arterial stiffness in isolated systolic hypertension. Hypertension 2009; 54: 409-13.

[65] Doumas M, Athyros V, Katsiki N, Reklou A, Lazaridis A, Karagiannis A. The effect of antihypertensive drugs on arterial 
stiffness and central hemodynamics: not all fingers are made the same. Open J Hypertens 2013 [in press].

[66] Briet M, Schiffrin EL. Treatment of arterial remodeling in essential hypertension. Curr Hypertens Rep 2013; 15: 3-9.

[67] Liang J, Zhou N, Teng F, et al. Hemoglobin A1c levels and aortic arterial stiffness: the Cardiometabolic Risk in Chinese (CRC) study. PLoS One 2012; 7: e38485.

[68] Shen L, Zhang YG, Liu M, et al. Increased Arterial Stiffness in Subjects with Pre-diabetes among Middle Aged Population in Beijing, China. Biomed Environ Sci 2013; 26: 717-25.

[69] Chen Y, Huang Y, Li X, et al. Association of arterial stiffness with $\mathrm{HbAlc}$ in 1,000 type 2 diabetic patients with or without hypertension. Endocrine 2009; 36: 262-7.

[70] Nestel P. Relationship between arterial stiffness and glucose metabolism in women with metabolic syndrome. Clin Exp Pharmacol Physiol 2006; 33: 883-6.

[71] Zieman SJ, Kamineni A, Ix JH, et al. Hemoglobin A1c and arterial and ventricular stiffness in older adults. PLoS One 2012; 7: e47941.

[72] Choi SW, Shin MH, Yun WJ, et al. Association between hemoglobin A1c, carotid atherosclerosis, arterial stiffness, and peripheral arterial disease in Korean type 2 diabetic patients. J Diabetes Complicat 2011;25: 7-13.

[73] Shargorodsky M, Omelchenko E, Matas Z, Boaz M, Gavish D. Relation between augmentation index and adiponectin during oneyear metformin treatment for nonalcoholic steatohepatosis: effects beyond glucose lowering? Cardiovasc Diabetol 2012; 11: 61.

[74] Agarwal N, Rice SP, Bolusani H, et al. Metformin reduces arterial stiffness and improves endothelial function in young women with polycystic ovary syndrome: a randomized, placebo-controlled, crossover trial. J Clin Endocrinol Metab 2010; 95: 722-30.

[75] Kiyici S, Ersoy C, Kaderli A, et al. Effect of rosiglitazone, metformin and medical nutrition treatment on arterial stiffness, serum MMP-9 and MCP-1 levels in drug naive type 2 diabetic patients. Diabetes Res Clin Pract 2009; 86: 44-50.

[76] Ohira M, Endo K, Oyama T, et al. Improvement of postprandial hyperglycemia and arterial stiffness upon switching from premixed human insulin 30/70 to biphasic insulin aspart 30/70. Metabolism 2011; 60: 78-85.

[77] Harashima K, Hayashi J, Miwa T, Tsunoda T. Long-term pioglitazone therapy improves arterial stiffness in patients with type 2 diabetes mellitus. Metabolism 2009; 58: 739-45.

[78] Goldberg RB. Thiazolidinediones and vascular damage. Curr Opin Endocrinol Diabetes Obes 2007; 14: 108-15.

[79] Araki T, Emoto M, Teramura M, et al. Effect of adiponectin on carotid arterial stiffness in type 2 diabetic patients treated with pioglitazone and metformin. Metabolism 2006; 55: 996-1001.
[80] Nagayama D, Saiki A, Endo K, et al. Improvement of cardio-ankle vascular index by glimepiride in type 2 diabetic patients. Int J Clin Pract 2010; 64: 1796-801.

[81] Koren S, Shemesh-Bar L, Tirosh A, et al. The effect of sitagliptin versus glibenclamide on arterial stiffness, blood pressure, lipids, and inflammation in type 2 diabetes mellitus patients. Diabetes Technol Ther 2012; 14: 561-7.

[82] Nakamura T, Matsuda T, Kawagoe Y, et al. Effect of pioglitazone on carotid intima-media thickness and arterial stiffness in type 2 diabetic nephropathy patients. Metabolism 2004; 53: 1382-6.

[83] Forst T, Michelson G, Ratter F, et al. Addition of liraglutide in patients with Type 2 diabetes well controlled on metformin monotherapy improves several markers of vascular function. Diabet Med 2012; 29: 1115-8.

[84] Kim NH, Kim HY, An H, et al. Effect of cilostazol on arterial stiffness and vascular adhesion molecules in type 2 diabetic patients with metabolic syndrome: a randomised, double-blind, placebo-controlled, crossover trial. Diabetol Metab Syndr 2013; 5: 41.

[85] Athyros VG, Hatzitolios AI, Karagiannis A, et al. IMPERATIVE Collaborative Group. IMproving the imPlemEntation of cuRrent guidelines for the mAnagement of major coronary hearT disease rIsk factors by multifactorial interVEntion. The IMPERATIVE renal analysis. Arch Med Sci 2011; 7: 984-92.

[86] Athyros VG, Ganotakis E, Kolovou GD, et al. Assessing The Treatment Effect in Metabolic Syndrome Without Perceptible Diabetes (ATTEMPT) Collaborative. Assessing the treatment effect in metabolic syndrome without perceptible diabetes (ATTEMPT): a prospective-randomized study in middle aged men and women. Curr Vasc Pharmacol 2011; 9: 647-57.

[87] Athyros VG, Mikhailidis DP, Didangelos TP, et al. Effect of multifactorial treatment on non-alcoholic fatty liver disease in metabolic syndrome: a randomised study. Curr Med Res Opin 2006; 22: 87383.

[88] Zhao XH, Xu ZR, Zhang Q, Gu HF, Yang YM. Effect of intensive multifactorial treatment on the intima-media thickness of large arteries in patients with new-onset type 2 diabetes mellitus. J Zhejiang Univ Sci B 2012; 13: 378-85.

[89] Janssen PG, Gorter KJ. Stolk RP, Rutten GE. Randomised controlled trial of intensive multifactorial treatment for cardiovascular risk in patients with screen-detected type 2 diabetes: 1-year data from the ADDITION Netherlands study. Br J Gen Pract 2009; 59: 43-8.

[90] Johansen NB, Charles M, Vistisen D, et al. Effect of intensive multifactorial treatment compared with routine care on aortic stiffness and central blood pressure among individuals with screendetected type 2 diabetes: the ADDITION-Denmark study. Diabetes Care 2012; 35: 2207-14.

Received: October 25, 2013

Revised: October 26, 2013

Accepted: October 26, 2013

(C) Katsiki et al.; Licensee Bentham Open.

This is an open access article licensed under the terms of the Creative Commons Attribution Non-Commercial License (http://creativecommons.org/licenses/by-nc/3.0/) which permits unrestricted, non-commercial use, distribution and reproduction in any medium, provided the work is properly cited. 